\title{
2004s-54 \\ Market Incompleteness and the Equity Premium Puzzle: Evidence from State-Level Data
}

\author{
Kris Jacobs, Stephane Pallage, \\ Michel A. Robe
}

Série Scientifique
Scientific Series

Montréal

Novembre 2004

(C) 2004 Kris Jacobs, Stephane Pallage, Michel A. Robe. Tous droits réservés. All rights reserved. Reproduction partielle permise avec citation du document source, incluant la notice C.

Short sections may be quoted without explicit permission, if full credit, including (C) notice, is given to the source.
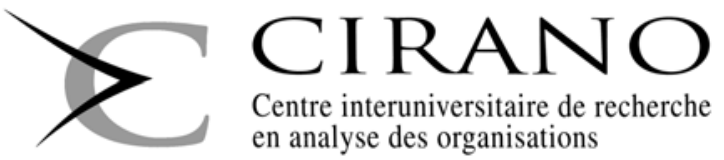

Centre interuniversitaire de recherche en analyse des organisations 


\section{CIRANO}

Le CIRANO est un organisme sans but lucratif constitué en vertu de la Loi des compagnies du Québec. Le financement de son infrastructure et de ses activités de recherche provient des cotisations de ses organisations-membres, d'une subvention d'infrastructure du Ministère du Développement économique et régional et de la Recherche, de même que des subventions et mandats obtenus par ses équipes de recherche.

CIRANO is a private non-profit organization incorporated under the Québec Companies Act. Its infrastructure and research activities are funded through fees paid by member organizations, an infrastructure grant from the Ministère du Développement économique et régional et de la Recherche, and grants and research mandates obtained by its research teams.

PARTENAIRE MAJEUR

$$
\text { Les organisations-partenaires / The Partner Organizations }
$$

. Ministère du Développement économique et régional et de la Recherche [MDERR]

PARTENAIRES

. Alcan inc.

. Axa Canada

. Banque du Canada

. Banque Laurentienne du Canada

. Banque Nationale du Canada

. Banque Royale du Canada

. Bell Canada

. BMO Groupe Financier

. Bombardier

. Bourse de Montréal

. Caisse de dépôt et placement du Québec

. Développement des ressources humaines Canada [DRHC]

. Fédération des caisses Desjardins du Québec

. GazMétro

. Hydro-Québec

. Industrie Canada

. Ministère des Finances du Québec

. Norshield Asset Management (Canada) Ltd.

. Pratt \& Whitney Canada Inc.

. Raymond Chabot Grant Thornton

. Ville de Montréal

. École Polytechnique de Montréal

. HEC Montréal

. Université Concordia

. Université de Montréal

. Université du Québec

. Université du Québec à Montréal

. Université Laval

. Université McGill

. Université de Sherbrooke

Associe A :

. Institut de Finance Mathématique de Montréal (IFM²)

. Laboratoires universitaires Bell Canada

. Réseau de calcul et de modélisation mathématique $\left[\mathrm{RCM}^{2}\right]$

. Réseau de centres d'excellence MITACS (Les mathématiques des technologies de l'information et des systèmes complexes)

Les cahiers de la série scientifique (CS) visent à rendre accessibles des résultats de recherche effectuée au CIRANO afin de susciter échanges et commentaires. Ces cahiers sont écrits dans le style des publications scientifiques. Les idées et les opinions émises sont sous l'unique responsabilité des auteurs et ne représentent pas nécessairement les positions du CIRANO ou de ses partenaires.

This paper presents research carried out at CIRANO and aims at encouraging discussion and comment. The observations and viewpoints expressed are the sole responsibility of the authors. They do not necessarily represent positions of CIRANO or its partners. 


\title{
Market Incompleteness and the Equity Premium Puzzle: Evidence from State-Level Data*
}

\author{
Kris Jacobs ${ }^{\dagger}$, Stephane Pallage ${ }^{t}$, Michel A. Robe $e^{\S}$
}

\begin{abstract}
Résumé / Abstract
Ce papier étudie l'importance de la complétude du marché en comparant le taux d'aversion au risque estimé dans le cas de marchés complets et incomplets. Dans le cas de marchés incomplets, nous utilisons des données de consommation de 50 états américains. Bien que l'utilisation de données agrégées au niveau des états est conceptuellement moins justifiée que l'utilisation de données individuelles, ce choix est préférable du fait que les données agrégées sont moins sujettes aux erreurs de mesures. Nous trouvons que le taux d'aversion au risque sous l'hypothèse de marchés incomplets est plus petit. De plus, la prise en compte du deuxième et du troisième moment de la distribution transversale de la croissance de la consommation dans le pricing kernel réduit le taux d'aversion au risque estimé. Ces résultats suggèrent que l'incomplétude du marché devrait être regardé comme une composante importante de la solution du puzzle de la prime d'équité.
\end{abstract}

Mots clés : hétérogénéité, risque inhérent à la consommation, marchés incomplets, modèle d'évaluation d'actif basé sur la consommation, aversion au risque, puzzle de la prime d'équité

This paper investigates the importance of market incompleteness by comparing the rates of risk aversion estimated from complete and incomplete markets environments. For the incomplete-markets case, we use consumption data for 50 U.S. states. While the use of state-level data is conceptually inferior to the use of data on individual consumption, it may be preferable because state-level data are less susceptible to measurement errors. We find that the rate of risk aversion under the incompletemarkets setup is much lower. Furthermore, including the second and third moments of the crosssectional distribution of consumption growth in the pricing kernel lowers the estimate of risk aversion. These findings suggest that market incompleteness ought to be seen as an important component of solutions to the equity premium puzzle.

Keywords: heterogeneity, idiosyncratic consumption risk; incomplete markets; consumption-based asset pricing model; risk aversion; equity premium puzzle

Codes JEL : G12

\footnotetext{
${ }^{*}$ We thank without implication Albert Marcet and Chris Telmer for useful discussions, and Steve Heston and seminar participants at the University of Maryland and George Washington University for helpful comments. We are very grateful to Marco del Negro for his help with state-level retail sales and CPI data. Jacobs would like to acknowledge FQRSC, SSHRC and IFM2 for financial support. Pallage's research was financially supported by FCAR/FQRSC; Robe's, by a Kogod endowed fellowship.

${ }^{\dagger}$ CIRANO and Department of Finance, Faculty of Management, McGill University, 1001 Sherbrooke Street West, Montreal, QC, Canada, H3A 1G5, tel: 514-398-4025, email: kris.Jacobs@mcgill.ca.

${ }^{\ddagger}$ CIRPEE and Department of Economics, Université du Québec à Montréal, C.P. 8888 Succursale Centre-Ville, Montreal, Québec, Canada, H3C 3P8, tel : 514-987-3000\#8370, email : pallage.stephane@uquam.ca

$\S$ Finance Department, Kogod School of Business at American University, 4400 Massachusetts Avenue NW, Washington, DC 20016, tel. 202-885-1880, email: mrobe@american.edu.
} 


\section{Introduction}

The equity premium puzzle constitutes one of the central research questions in financial economics. Using a representative agent construction with time-separable, constant relative risk aversion preferences (TS-CRRA), Mehra and Prescott (1985) demonstrate that the standard consumption-based asset pricing model of Lucas (1978) and Breeden (1979) is unable to explain the historically observed premium of equity over a riskless investment. This finding can be interpreted in several ways. It may indicate that the workhorse model of rational behavior in financial markets does not work, possibly suggesting that irrational behavior explains security prices. Alternatively, it may be that some of the maintained hypotheses in Mehra and Prescott's empirical analysis are incorrect yet the fundamental logic of the consumption-based model is adequate.

This paper is part of an extensive literature that attempts to explain Mehra and Prescott's findings by maintaining the basics of their theoretical consumption-based framework, while altering some other maintained assumptions. One part of this literature maintains the representative-agent framework but uses a utility function other than TS-CRRA. That approach has enjoyed some success in explaining the equity premium puzzle. ${ }^{1}$ The present paper is part of another part of this literature, which maintains the TS-CRRA utility function but relaxes the representative-agent assumption. Several papers have demonstrated that the full-insurance assumption that underlies the representative-agent framework is not supported by the data. ${ }^{2}$ Jacobs (1999), Brav, Constantinides and Geczy (2002, henceforth BCG), and Constantinides (2002) use data on individual consumption to demonstrate that the analysis of Euler equations that hold under incomplete markets yields low rates of risk aversion, as opposed to the large rates of risk aversion needed to explain the equity premium in the Mehra-Prescott (1985) setup. ${ }^{3}$ This evidence suggests that market incompleteness may help resolve the equity premium puzzle, even though Cogley (2002) finds evidence to the contrary.

The main problem with this second part of the literature is the quality of the individual consumption data used to conduct the empirical analyses. Existing data sets have a relatively limited

\footnotetext{
${ }^{1}$ See Sundaresan (1989), Abel (1990), Constantinides (1990), Epstein and Zin (1991), Ferson and Constantinides (1991), Cochrane and Hansen (1992), Heaton (1995), Campbell and Cochrane (1999), and Bansal and Yaron (2003).

${ }^{2}$ See Cochrane (1991), Mace (1991), and Hayashi, Altonji and Kotlikoff (1996).

${ }^{3}$ Mankiw and Zeldes (1991) and Vissing-Jorgensen (2002) provide related evidence on the importance of asset market participation. Telmer (1993), Heaton and Lucas (1996), Telmer, Storesletten and Yaron (2001), and Constantinides, Donaldson and Mehra (2002) provide evidence on the relevance of market incompleteness using a simulation-based approach. See Constantinides (2002) for a more elaborate discussion.
} 
time-series dimension, and are therefore ill-suited for testing rational-expectations models (Chamberlain, 1984). It is also obvious that some of the fluctuations in consumption present in data sets such as the Consumer Expenditure Survey and the Panel Study of Income Dynamics are due to measurement error - yet it is not obvious how to correct for it.

More extensive and reliable data sets containing data on individual consumption can obviously not be created overnight. It therefore becomes important to shed light on this issue using alternative methods and/or data sets. This paper attempts to do this by replicating some of the tests in BCG (2002) using a data set on consumption growth in 50 U.S. states for the period 1963-1995 (Del Negro, 2002). There are differences in the consumption patterns across states, and the objective is to learn about market incompleteness by interpreting state consumption and heterogeneity across states as a proxy for individual consumption and heterogeneity across consumers. One particular way to interpret this proxy is to think of it as the consumption of a synthetic cohort, as used in this literature by Browning, Deaton, and Irish (1985) and Attanasio and Weber (1995).

It is clear that this approach has serious limitations, and at some level it contains methodological contradictions. Effectively, it amounts to assuming the existence of a representative consumer at the state level while questioning the relevance of the representative-agent assumption at the economywide level. We believe that, despite these limitations, our empirical findings are of interest provided they are interpreted conservatively and cautiously.

Our empirical exercise consists of determining the rate of relative risk aversion that solves the Euler equation associated with the equity premium. The benchmark for this analysis solves the Euler equation for the representative-agent economy, using aggregate consumption data for the same period. Our main conclusion is that the rate of risk aversion for the incomplete-markets case is much lower than the rate of risk aversion for the representative-agent case. We also present evidence indicating that higher moments play a critical role in this regard. Including the crosssectional variance in a Taylor series expansion of the pricing kernel lowers the estimate of the rate of risk aversion, compared to the case where only the cross sectional average consumption growth is included. This indicates that, conditional on the first moment, the second moment of the crosssectional distribution is negatively correlated with the equity premium. Including cross-sectional skewness further lowers our estimate of the rate of risk aversion, indicating positive (conditional) correlation between the third moment and the equity premium. Including cross-sectional kurtosis does not, however, help to further resolve the equity premium puzzle.

The paper proceeds as follows. Section 2 outlines the analytical framework. Section 3 discusses the data. Section 4 summarizes the empirical results. Section 5 concludes. 


\section{Analytical Framework}

We investigate the equity premium puzzle under the maintained assumption of TS-CRRA utility. With $\gamma$ denoting the rate of relative risk aversion, this leads to the following optimality condition for consumer $i$ with respect to her choice of asset $j$ :

$$
E\left[\beta\left(c g_{i, t}\right)^{-\gamma} R_{j, t} \mid \Omega_{t-1}\right]=1
$$

where $c g_{i, t}=c_{i, t} / c_{i, t-1}, c_{i, t}$ is the consumption of consumer $i$ in period $t, \beta$ denotes the rate of time preference, $R_{j, t}$ is the gross rate of return on asset $j$ between periods $t-1$ and $t$, and $\Omega_{t-1}$ is the information set in period $t-1$. In our empirical application we do not use data on individual consumption, but data on state consumption. Henceforth we will therefore refer to the consumption of state $i$ rather than consumer $i$. We investigate the returns on two assets, the market return, denoted $R_{M A}$, and the return on the risk-free asset, denoted $R_{R F}$. We focus on the difference between the Euler equations (1) for these two assets:

$$
E\left[\beta\left(c g_{i, t}\right)^{-\gamma}\left(R_{M A, t}-R_{R F, t}\right) \mid \Omega_{t-1}\right]=0
$$

The empirical analysis of (2) depends on the choice of information set $\Omega_{t-1}$. We investigate the particular case where $\Omega_{t-1}$ exclusively contains a constant. The resulting differenced Euler equation is usually referred to as an unconditional Euler equation. Analyzing it amounts to an investigation of the equity premium puzzle, which refers to the difference in the unconditional mean return between the market and a risk-free investment. Henceforth we therefore focus on

$$
E\left[\beta\left(c g_{i, t}\right)^{-\gamma}\left(R_{M A, t}-R_{R F, t}\right)\right]=0,
$$

assuming without loss of generality that the constant is equal to one. It must be noted that (3) amounts to one equation in the two unknowns, $\beta$ and $\gamma$. However, $\beta$ is clearly not identifiable from (3) and therefore we set it equal to one in the empirical analysis. While this choice clearly has certain empirical implications (it scales the pricing errors), it does not affect the central issue of interest in this paper, which is the level of the rate of risk aversion $\gamma$ implied by the data.

In (1), (2) and (3), $\beta\left(c g_{i, t}\right)^{-\gamma}$ is a pricing kernel that discounts future returns. Part of the asset pricing literature consists of the search for an appropriate pricing kernel, and this is the exclusive focus of this paper. To economize on notation, it therefore helps to rewrite (3) as

$$
E\left[M_{t}\left(R_{M A, t}-R_{R F, t}\right)\right]=0 .
$$


where $M_{t}$ is the pricing kernel. Rather than repeating the (differenced) Euler equation, we can therefore simply refer to (4) and limit ourselves to a discussion of the different pricing kernels $M_{t}$.

\subsection{Incomplete-markets pricing kernel}

Equation (3) is an example of a pricing kernel, with $M_{t} \equiv M_{i t}=\beta\left(c g_{i, t}\right)^{-\gamma}$. We could empirically analyze this kernel by using time series data on consumption growth in each of the 50 states separately. Instead, we use the fact that, if (3) holds for each state $i(i=1, \ldots, 50)$, then it must be true also that $\frac{1}{50} \sum_{i=1}^{50} \beta E\left[\left(c g_{i, t}\right)^{-\gamma}\left(R_{M A, t}-R_{R F, t}\right)\right]=0$ and, hence, that $\beta E\left[\frac{1}{50} \sum_{i=1}^{50}\left(c g_{i, t}\right)^{-\gamma}\left(R_{M A, t}-\right.\right.$ $\left.\left.R_{R F, t}\right)\right]=0$. We focus on this restriction, like Jacobs (1999) and Brav, Constantinides and Geczy (2002). This approach amounts to analyzing the kernel

$$
M_{t}=\frac{1}{N} \sum_{i=1}^{N} \beta\left(c g_{i, t}\right)^{-\gamma}
$$

where $N$ is the number of U.S. states.

The exercise we conduct answers the following question: if markets are not complete, then what is the rate of risk aversion implied by the data if we assume that consumption heterogeneity in the economy is adequately captured by the heterogeneity in state consumption? ${ }^{4}$ At first blush, this exercise might seem contrived - and indeed it contains inconsistencies at the methodological level, because effectively it amounts to positing a representative agent at the state level while ruling out the existence of a representative agent for the United States as a whole. The motivation for the analysis is entirely data-driven. While the use of state-level data is conceptually inferior to

\footnotetext{
${ }^{4}$ We implicitly assume that risk aversion is the same in all individual states. Our motivation is as follows. The state data indicate that aggregation considerably smooths consumption growth, and we know from Hansen and Jagannathan (1991) that this will have important consequences for the implied rate of relative risk aversion. An analysis of the pricing kernel $M_{t} \equiv M_{i t}=\beta\left(c g_{i, t}\right)^{-\gamma}(i=1, \ldots, 50)$ would yield a number of estimates of the rate of risk aversion, one for each state. If one questions the interpretation of estimates of risk aversion obtained within the representative-agent framework, however, then one would probably be equally sceptical about estimates of risk aversion obtained under the maintained assumption that a representative consumer exists at the state level. We therefore conduct a different empirical exercise, where we take all the cross-sectional information into account to estimate a single rate of risk aversion. The resulting estimate indicates how the volatile consumption growth in some states changes inference on risk aversion compared to the representative-agent benchmark that is standard in the literature. The precise estimate of risk aversion obtained in this analysis is of secondary importance compared to the estimate of the difference between the risk aversion implied by the representative-agent benchmark and the incomplete-markets benchmark. The relevant issue is the magnitude of the difference between these two estimates. A reliable estimate of risk aversion can only be obtained using household-level data. We therefore focus on an analysis of the kernel (5) rather than on a state-by-state analysis.
} 
the use of data on individual consumption, it may be preferable because state-level data are less susceptible to measurement error problems. In fact, one can think of our empirical exercise as an analysis involving cohort data, in the spirit of Attanasio and Weber (1995).

\subsection{Complete-markets benchmark}

As mentioned above, the central message in our analysis is not the rate of risk aversion but the difference in the risk aversion between the incomplete- and complete-markets economies. The reference point is an analysis of the representative-agent pricing kernel, which is given by

$$
M_{t}=\beta\left(c g_{t}\right)^{-\gamma}
$$

where $c g_{t}=c_{t} / c_{t-1}$ and $c_{t}$ is aggregate consumption at time $t$. We implement this representativeagent pricing kernel using two types of data. First, we use U.S. aggregate per capita consumption in period $t$ for $c_{t}$. Second, we define $c_{t}$ as $\frac{1}{N} \sum_{i=1}^{N} c_{i, t}$, where $c_{i, t}$ is per capita consumption in U.S. state $i$. This second definition gives relatively more weight to the consumption growth series in states in states with lower-than-average populations.

\subsection{Importance of the cross-sectional moments}

We complement our analysis of the incomplete-markets pricing kernel (5) and the representativeagent pricing kernel (6) with a more detailed analysis of the impact of the higher moments of the cross-sectional distribution of consumption growth. Different moments of this distribution affect risk premia in different ways, and therefore this type of analysis contributes to our understanding of the strengths and weaknesses of the TS-CRRA utility representation that is being studied. Mankiw (1986) points out the relevance of this approach, and Brav, Constantinides and Geczy (2002) and Cogley (2002) provide an empirical analysis using a TS-CRRA utility function and data from the Consumer Expenditure Survey.

We closely follow Brav, Constantinides and Geczy (2002) in our analysis. By expanding (5) using a fourth-order Taylor series expansion, we obtain

$$
\begin{aligned}
M_{t}= & \beta a c g_{t}^{-\gamma}\left[1+0.5 \gamma(\gamma+1) \frac{1}{N} \sum_{i=1}^{N}\left(\frac{c g_{i, t}}{a c g_{t}}-1\right)^{2}-\frac{1}{6} \gamma(\gamma+1)(\gamma+2)\right. \\
& \left.\frac{1}{N} \sum_{i=1}^{N}\left(\frac{c g_{i, t}}{a c g_{t}}-1\right)^{3}+\frac{1}{24} \gamma(\gamma+1)(\gamma+2)(\gamma+3) \frac{1}{N} \sum_{i=1}^{N}\left(\frac{c g_{i, t}}{a c g_{t}}-1\right)^{4}\right]
\end{aligned}
$$


where $a c g_{t}=\frac{1}{N} \sum_{i=1}^{N} c g_{i, t}$ represents average consumption growth. We also investigate the following special cases of (7), obtained by taking lower-order Taylor series expansions.

$$
\begin{aligned}
& M_{t}=\beta a c g_{t}^{-\gamma} \\
& M_{t}=\beta a c g_{t}^{-\gamma}\left[1+0.5 \gamma(\gamma+1) \frac{1}{N} \sum_{i=1}^{N}\left(\frac{c g_{i, t}}{a c g_{t}}-1\right)^{2}\right] \\
& M_{t}=\beta a c g_{t}^{-\gamma}\left[1+0.5 \gamma(\gamma+1) \frac{1}{N} \sum_{i=1}^{N}\left(\frac{c g_{i, t}}{a c g_{t}}-1\right)^{2}-\frac{1}{6} \gamma(\gamma+1)(\gamma+2) \frac{1}{N} \sum_{i=1}^{N}\left(\frac{c g_{i, t}}{a c g_{t}}-1\right)^{3}\right] .
\end{aligned}
$$

By comparing the rate of risk aversion implied by (8) with (9) and subsequently with (10) and (7), we get an indication of how higher moments of the cross-sectional distribution help in resolving the equity premium puzzle. In particular, note that in order to resolve the puzzle, the cross-sectional variance and kurtosis need to be negatively correlated with the equity premium (conditional on lower moments), while the cross-sectional skewness needs to be positively correlated. Also note that the analysis of (8) is different from the analysis of the representative-agent pricing kernel (6), because in (8) the averaging is over consumption growth, instead of the level of consumption.

\subsection{Robustness}

To assess the robustness of our results, we also analyze the incomplete-markets pricing kernel derived by Constantinides and Duffie (1996). This kernel is based on the first two moments of the cross-sectional distribution of consumption growth, as in (9), but uses the natural logarithm of consumption growth. This alternative kernel also differs from the others in that it is derived in an equilibrium setup, under the assumption that idiosyncratic income shocks are multiplicative and i.i.d. lognormal.

$$
M_{t}=\beta c g_{t}^{-\gamma} \exp \left[0.5 \gamma(\gamma+1) \frac{1}{N} \sum_{i=1}^{N}\left(\log \left(c g_{i, t}\right)-\frac{1}{N} \sum_{i=1}^{N} \log \left(c g_{i, t}\right)\right)^{2}\right]
$$

Another issue is that pricing kernel (5) assigns the same weight to per capita consumption growth in small and large U.S. states. A natural question is whether the results are robust to using population-based weights instead. To answer this question, we also analyze the kernel

$$
M_{t}=\sum_{i=1}^{N} \beta \frac{1}{w_{i}}\left(c g_{i, t}\right)^{-\gamma}
$$

where $N$ is the number of U.S. states; and $w_{i} \equiv \frac{1}{T} \sum_{i=1}^{T} w_{i, t}$ is the weight assigned to state $i$, with $T$ equal to the number of years in the sample and $w_{i, t} \equiv \frac{\text { Population of state } i \text { in year } t}{\text { U.S. population in year } t}$. 


\section{Data and descriptive statistics}

This section discusses different aspects of data construction.

\subsection{Consumption data}

The empirical analysis is based on data for real nondurables and services (NDS) consumption for 50 U.S. states. This approach yields annual data on state-level NDS consumption growth for the 50 states for $1963-1995$.

Specifically, for each of the 50 U.S. states and for the United States as a whole, we use real per capita private consumption data over the 1962-1995 period. Quarterly state consumption figures are not available, so we rely on annual data. State-level consumption series are constructed from proprietary retail sales data originally published by Sales and Marketing Management (SMM), using procedures described in Del Negro (2002). ${ }^{5}$ Those retail sales are only a proxy for private consumption but, as Ostergaard, Sorensen and Yosha (2002) point out, they are the best data available at the state level. We focus on non-durable private consumption. ${ }^{6}$ For each state, we calculate non-durable private consumption for a given year by multiplying the relevant retail sales by the ratio of total U.S. private consumption (Bureau of Economic Analysis, BEA 2002) to overall U.S. retail sales (SMM) for that year. This re-scaling presents the advantage of adjusting our consumption estimates for the consumption of services not included in the original retail sales series. ${ }^{7}$ We deflate all these consumption series using the U.S. CPI. ${ }^{8}$

\subsection{Returns data}

We use four different measures of the equity premium to investigate the robustness of the results. Two are based on equally-weighted stock returns, and two on value-weighted stock returns, all obtained from the Center for Research in Security Prices (CRSP). For each case, we construct a

\footnotetext{
${ }^{5}$ We are very grateful to Marco del Negro for providing the retail sales data and his state CPI estimates in electronically readable format.

${ }^{6}$ We repeated the empirical analyses using total private consumption in robustness tests, and obtained comparable results. We do not report these results here, because the between-periods separability assumption is questionable for durable goods.

${ }^{7}$ SMM non-durable retail sales, summed up across all states, are a very close substitute for U.S. private consumption expenditures on non-durable goods (to the exclusion of services) reported by the Bureau of Economic Analysis. Between 1960-95, the mean ratio of the two series is 1.02 and the correlation between them is 0.99 .

${ }^{8}$ Our conclusions are robust to using state CPI figures.
} 
first measure of the return for year $t+1$ by computing the return from December 31 of year $t$ to December 31 of year $t+1$. We will refer to the resulting equity premium as the "Decemberto-December equity premium." The other two returns series are obtained by taking the average of the one-year January-to-January,..., December-to-December returns (an average of 12 one-year returns). We will refer to the resulting equity premium as the "averaged" equity premium. It is not clear a priori which return series is more appropriate given the construction of consumption growth, and therefore we report results based on both approaches. In all cases, the equity premium is obtained by subtracting a measure of the riskless return which is constructed in a similar fashion as the series for the stock return. The riskless return is constructed using yields on one-year treasury bills obtained from CRSP.

\subsection{Summary statistics}

Table 1 presents some descriptive statistics that are helpful to interpret the empirical results. Table 1A presents descriptive statistics for state consumption growth. We implement a calibration for the representative-agent model using U.S. aggregate NDS consumption data for the same period and we present descriptive statistics for these data for comparison purposes. We also implement the representative-agent model using consumption levels that are the (equally-weighted) average of state consumption, and we also present descriptive statistics for those data. The stylized facts in Table 1A can be summarized very briefly. The time series for U.S. aggregate consumption growth has very similar properties to the consumption-growth time series based on the equally-weighted average of the state data. While for each individual state the average consumption growth is similar to that for aggregate U.S. data, the standard deviation is much higher and the state-level data contain more extreme outliers. Table 1B presents descriptive statistics on the four measures of the equity premium. An important observation is that the equally-weighted returns are higher than the value-weighted returns, due to the better performance of small-firm stocks over this sample period.

Table 2 presents the correlations between the equity premium series and the moments that enter the incomplete-markets pricing kernel, as well as the average consumption growth data used in the representative-agent pricing kernel. We present correlations and figures for the value-weighted equity premium series only, because the results for the corresponding equally-weighted series are very similar. Interestingly, it can be seen that the correlation results are broadly unaffected by the construction of the returns series. Specifically, while the exact magnitudes of the various correlation coefficients vary with the return series, their signs do not. The equity premium is positively 
correlated with the cross-sectional mean and skewness of consumption growth, and negatively correlated with the cross-sectional variance and kurtosis. Likewise, the correlations of the respective equity premium series with the components of the representative-agent pricing kernel in (6) are all positive, although they are weaker for the December-to-December equity premium in rows 2 and 3 of Table 2A (approximately 0.05 ) than for the averaged equity premium in rows 2 and 3 of Table 2B (approximately 0.24 ). The similarity between the numbers in rows 2 and 3 of Tables $2 \mathrm{~A}$ and $2 \mathrm{~B}$ confirms that the first moment (obtained by averaging over state consumption growth) is very highly correlated with U.S. consumption growth (obtained by computing the growth rate of aggregate U.S. consumption) and average consumption growth (obtained by averaging over the level of state consumption).

To provide some more intuition, Figure 1 plots the first four moments of the cross-sectional distribution of consumption growth over time as well as the two equity premium time series used in Table 2. This figure gives a rough idea of the comovements between the cross-sectional moments and the equity premium, and allows the reader to visualize which sub-periods determine the comovements between the equity premium and the moments summarized by the correlations in Table 2. Note that these comovements only provide a partial answer regarding the role of higher moments in the resolution of the equity premium puzzle. While it is instructive to interpret, for instance, the correlation of the third or fourth moment with the equity premium, these comovements are most relevant conditional on the presence of the first and second moments in the pricing kernel. It is not the correlation of the higher moments with the equity premium that is relevant, but the conditional correlation, where the conditioning is done on the lower moments. Nevertheless, the graphical representation of these comovements provides some useful insight into the empirical results discussed below.

\section{Empirical results}

Table 3 presents our empirical results. We investigate nine different pricing kernels, and as discussed in Section 3 we repeat the analysis for four different computations of the equity premium. Each entry in the table gives the rate of risk aversion that sets the pricing error based on (4) equal to zero. For all candidate pricing kernels $M_{t}$, the pricing error is computed as

$$
\frac{1}{T} \sum_{t=1}^{T} M_{t}\left(R_{M A, t}-R_{R F, t}\right)=0 .
$$


The empirical exercise is therefore an extremely simple one: it consists of minimizing (13) with respect to the risk aversion parameter $\gamma$ (Recall that $\beta$ can not be identified from the differenced Euler equation. It is set equal to one in the empirical exercise.)

The pattern of $\gamma$ is the same across pricing kernels (i.e., across rows) regardless of the construction of returns. In general, equally-weighted returns lead to a higher estimate of the rate of relative risk aversion than value-weighted returns. Also, the averaged returns lead to lower estimates of the rate of risk aversion than do the December-December returns. Overall, the differences across columns are surprisingly modest and we can therefore focus on discussing only one of the columns. We choose the third column, i.e., the results for the value-weighted averaged returns.

The third row indicates that the rate of risk aversion that solves the standard incompletemarkets kernel (5) is equal to 18.19. Contrast this with the first and second rows, which contain the results for the standard representative-agent kernel (6). In the first row aggregate consumption is taken to be U.S. consumption, while in the second row it is taken to be the average of state consumption. In both cases the implied rate of risk aversion is much higher than the rate in row 3, clearly indicating the importance of market incompleteness, and the difficulty inherent in interpreting estimates of behavioral parameters obtained from aggregate data. Rows 4, 5, 6, and 7 present the rate of risk aversion implied by the pricing kernels (8), (9), (10) and (7) respectively. The most important conclusion is of course that, up to the third moment, the implied rate of risk aversion decreases sharply with the inclusion of each successive higher moment, indicating that the conditional correlation between the first three moments and the equity premium has the sign predicted by theory. These findings contrast with those of Cogley (2002), who finds that higher cross-sectional moments do not help to resolve the equity premium puzzle. They are consistent with the findings of BCG (2002), who document the importance of the cross-sectional variance and skewness of the distribution of consumption growth for the equity premium puzzle.

Comparing the results with the pricing kernels in rows 4 through 7 allows for three other interesting observations. First, the rate of risk aversion implied by kernel (8) in row 4, which uses only the cross-sectional mean of consumption growth, is approximately equal to the risk aversion implied by the standard representative-agent kernel in row 1. Second, the inclusion of the fourth moment in kernel (7), in row 7, does not seem to much lower the estimate of the rate of risk aversion. Depending on the construction of the return series, it may even slightly increase that estimate. Third, the estimate of risk aversion obtained using a kernel with three moments in row 6 is just a bit higher than the one for the standard incomplete-markets kernel in row 3 . The most logical interpretation of these findings is that the fourth moment does not help to further resolve 
the equity premium, but it may also be the case that moments higher than the fourth are important or that the fourth moment is imprecisely estimated because of the paucity of data. ${ }^{9}$

The last two rows in Table 3 provide evidence that our results are robust to using alternative incomplete-markets pricing kernels. We analyze the Constantinides and Duffie (1996) kernel (11) in row 8 and kernel (12) in row 9. This final kernel is a differently-weighted version of the standard incomplete-markets pricing kernel (5), with population-based weights in (12) replacing equal weights for each state in (5). Reassuringly, we obtain qualitatively similar results when using (11) instead of (9) or (5) and when using (12) instead of (5). In particular, the implied rates of risk aversion are just a bit higher than with kernel (5) and remain much lower than those based on the representativeagent kernel in row 2. The numbers based on the Constantinides and Duffie kernel in row 8 are also not very different in most cases from the results based on the incomplete-markets kernel (9) with the first two moments in row 5. These results are somewhat different from those in BCG (2002), who report that the pricing error increases with risk aversion in this case.

There are a few technical details that have to be cleared up. First, even though (13) represents one equation in one unknown, it is not always possible to find a rate of risk aversion that solves the equation. The reason for this can be seen from Figure 2, which graphs the pricing error as a function of the rate of risk aversion for different pricing kernels. In all four panels, value-weighted returns are used. The top two panels correspond to the standard incomplete-markets kernel in row 3 of Table 3. The bottom two panels correspond to the incomplete-markets kernel with two moments in row 5. The left panels use December-to-December returns, and the right panels use averaged returns. It is always the case that, for moderate rates of risk aversion, the pricing errors are lower than under risk neutrality. However, while in most cases the pricing error further decreases and eventually becomes negative as risk aversion goes up, in some cases it increases again and the pricing error never becomes negative, implying that there is no rate of risk aversion that makes the pricing error exactly zero. Which case obtains depends on the cross-sectional pattern of consumption growth in periods when the equity premium is negative, but it can be easily understood that both cases are possible and that a different case can obtain dependent on the construction of returns. In those cases where the pricing error is never zero, we have listed the rate of risk aversion that yields the minimum pricing error in Table 3 . We indicate those cases with an asterisk.

\footnotetext{
${ }^{9}$ An alternative explanation is suggested by Dittmar (2002), who argues that the Taylor series expansion ought to be truncated after the third moment. His argument is motivated by the fact that it is difficult to sign the terms involving higher moments. Kimball (1993) provides a motivation for the sign of the term involving the third moment.
} 
Second, Table 3 does not address the statistical significance of the pricing errors. It is interesting to note in this respect that we are not necessarily looking for rates of risk aversion that set the pricing error exactly equal to zero (as in Table 3), but for rates of risk aversion that yield a pricing error that is statistically indistinguishable from zero. Figure 3 presents $95 \%$ confidence bands, assuming asymptotic normality. These confidence bands do not allow for serial correlation, but allowing for first- or second-order serial correlation does not dramatically affect the results. Note that alternatively significance could be assessed using bootstrapping as in BCG (2002). Confidence bands for the other cases in Table 3 are very similar. Despite the fact that the errors are fairly precisely estimated over a wide range of risk aversion, we always have a considerable range of risk aversion that generates pricing errors that are not statistically significantly different from zero.

\section{Conclusion}

The results in Jacobs (1999) and Brav, Constantinides and Geczy (2002) indicate that market incompleteness is critically important to understanding asset pricing puzzles. These papers document that the rates of risk aversion implied by restrictions from incomplete-markets economies are relatively small, between zero and four, which is radically different from the large rates of risk aversion implied by a representative-agent setup. One problem with these findings is that Cogley (2002) finds evidence that market incompleteness does not help much to resolve asset-pricing puzzles. Another problem is that all these studies rely on household consumption data that leave much to be desired. The time dimension of the data is limited; for some data sets, only food consumption is available. Most importantly, the consumption data are based on surveys of individuals and are thought to contain significant measurement error. It is therefore important to investigate this issue using alternative data sets.

This paper repeats a set of tests from this literature using data on consumption for U.S. states, and finds that the rate of risk aversion implied by incomplete-markets pricing kernels are much lower than those resulting from a representative-agent setup. This finding, together with the observation that higher moments up to the third help in explaining the equity premium puzzle, is the central message from this paper. We therefore conclude that the clear evidence in this paper on the inadequacy of the representative-agent setup, coupled with the remarkably consistent message in the papers that study individual data, suggest that the equity premium puzzle can at least be partially resolved by considering market incompleteness.

Some of the other empirical findings in this paper ought to be interpreted cautiously. Specifically, 
we feel that the absolute levels of the rate of risk aversion obtained in our empirical exercise are of somewhat less interest. After all, our analysis implicitly assumes the existence of a representative consumer at the state level. Given that we question the use of a representative U.S. consumer in empirical work, it is impossible to take the existence of a representative consumer at the state level seriously. It is clear that a large amount of heterogeneity has been averaged out with the construction of such representative consumers at the state level. In our opinion, it is necessary to further investigate existing data sets that contain individual consumption to learn more about the level of risk aversion in the population. If anything, the estimates in the present paper can be used as a very conservative upper bound.

\section{References}

Abel, Andrew B., 1990, Asset prices under habit formation and catching up with the Joneses, American Economic Review Papers and Proceedings 80, 38-42.

Attanasio, Orazio and Guglielmo Weber, 1995, Is consumption growth consistent with interteporal optimization? Evidence from the Consumer Expenditure Survey, Journal of Political Economy 103, 1121-1157.

Bansal, Ravi and Amir Yaron, 2004, Risks for the long run: A potential resolution of asset pricing puzzles, Journal of Finance 59, forthcoming.

Brav, Alon, George Constantinides and Christopher Geczy, 2002, Asset pricing with heterogeneous consumers and limited participation: Empirical evidence, Journal of Political Economy 110, 793-824.

Breeden, Douglas T., 1979, An intertemporal asset pricing model with stochastic consumption and investing opportunities, Journal of Financial Economics 7, 265-296.

Browning, Martin, Angus Deaton and Margaret Irish, 1985, A profitable approach to labor supply and commodity demands over the life-cycle, Econometrica 53, 503-544.

Campbell, John Y. and John Cochrane, 1999, By force of habit: A consumption-based explanation of aggregate stock market behaviour, Journal of Political Economy 107, 205-251.

Chamberlain, Gary, 1984, Panel Data, in Z. Griliches and M. Intriligator, eds.: Handbook of Econometrics, Vol. 2 (North-Holland, Amsterdam). 
Cochrane, John, 1991, A simple test of consumption insurance, Journal of Political Economy 99, 957-976.

Cochrane, John and Lars Peter Hansen, 1992, Asset pricing lessons for macroeconomics, in O. Blanchard and S. Fischer, eds.: 1992 NBER Macroeconomics Annual (National Bureau of Economic Research, Cambridge, MA).

Cogley, Timothy, 2002, Idiosyncratic risk and the equity premium: Evidence from the Consumer Expenditure Survey, Journal of Monetary Economics 49, 309-334.

Constantinides, George M., 1990, Habit formation: A resolution of the equity premium puzzle, Journal of Political Economy 98, 519-543.

Constantinides, George M., 2002, Rational asset prices, Journal of Finance 57, 1567-1591.

Constantinides, George M., and Darrell Duffie, 1996, Asset pricing with heterogeneous consumers, Journal of Political Economy 104, 219-240.

Constantinides, George M., Donaldson, John B. and Rajnish Mehra, 2002, Junior can't borrow: A new perspective on the equity premium puzzle, Quarterly Journal of Economics 117, 269-296.

Del Negro, Marco, 2002, Asymmetric shocks among U.S. states, Journal of International Economics $56,2,483-513$.

Dittmar, Robert, 2002, Nonlinear pricing levels, kurtosis preference, and evidence from the cross section of equity returns, Journal of Finance 57, 369-403.

Epstein, Larry G. and Stanley E. Zin, 1991, Substitution, risk aversion, and the temporal behavior of asset returns: An empirical analysis, Journal of Political Economy 99, 263-287.

Ferson, Wayne E. and George M. Constantinides, 1991, Habit persistence and durability in aggregate consumption: Empirical tests, Journal of Financial Economics 29, 199-240.

Hansen, Lars Peter and Ravi Jagannathan, 1991, Implications of security market data for models of dynamic economies, Journal of Political Economy 99, 225-262.

Hayashi, Fumio, Joseph Altonji and Lawrence Kotlikoff, 1996, Risk sharing across and within families, Econometrica 64, 261-294.

Heaton, John, 1995, An empirical investigation of asset pricing with temporally dependent preference specifications, Econometrica 63, 681-717. 
Heaton, John and Deborah Lucas, 1996, Evaluating the effects of incomplete markets for risk sharing and asset pricing, Journal of Political Economy 104, 443-487.

Jacobs, Kris, 1999, Incomplete markets and security prices: Do asset-pricing puzzles result from aggregation problems? Journal of Finance 54, 123-164.

Kimball, Miles, 1993, Standard risk aversion, Econometrica 61, 589-611.

Lucas, Robert E. Jr., 1978, Asset prices in an exchange economy, Econometrica 46, 1429-1445.

Mankiw, N. Gregory and Stephen P. Zeldes, 1991, The consumption of stockholders and nonstockholders, Journal of Financial Economics 29, 113-135.

Mace, Barbara, 1991, Full insurance in the presence of aggregate uncertainty, Journal of Political Economy 99, 928-956.

Mehra, Rajnish and Edward C. Prescott, 1985, The equity premium: A puzzle, Journal of Monetary Economics 15, 145-161.

Ostergaard, Charlotte, Bent E. Sorensen and Oved Yosha, 2002, Consumption and aggregate constraints: Evidence from U.S. states and Canadian provinces, Journal of Political Economy $110,634-645$.

Sundaresan, Suresh, 1989, Intertemporally dependent preferences and the volatility of consumption and wealth, Review of Financial Studies 2, 73-88.

Telmer, Chris I., 1993, Asset pricing puzzles and incomplete markets, Journal of Finance 48, 18031832

Telmer, Chris I., Kjetil Storesletten and Amir Yaron, 2001, Asset pricing with idiosyncratic risk and overlapping generations, GSIA working paper no. 1997-E226, Carnegie Mellon University. Revised, December 2001.

Vissing-Jorgensen, Annette, 2002, Limited asset market participation and the elasticity of intertemporal substitution, Journal of Political Economy 110, 825-853. 


\begin{tabular}{|c|c|c|c|c|}
\hline & Mean & Stdev. & Min. & Max. \\
\hline Alaska & 1.0279 & 0.0623 & 0.9210 & 1.2772 \\
\hline Alabama & 1.0214 & 0.0444 & 0.8957 & 1.1147 \\
\hline Arkansas & 1.0195 & 0.0371 & 0.9374 & 1.0837 \\
\hline Arizona & 1.0156 & 0.0480 & 0.9134 & 1.1718 \\
\hline California & 1.0057 & 0.0345 & 0.9362 & 1.0677 \\
\hline Colorado & 1.0160 & 0.0458 & 0.9053 & 1.1298 \\
\hline Connecticut & 1.0173 & 0.0677 & 0.8738 & 1.1619 \\
\hline Delaware & 1.0139 & 0.0591 & 0.8697 & 1.1552 \\
\hline Florida & 1.0147 & 0.0469 & 0.9259 & 1.1508 \\
\hline Georgia & 1.0191 & 0.0380 & 0.9487 & 1.1038 \\
\hline Hawaii & 1.0280 & 0.0493 & 0.9157 & 1.1627 \\
\hline lowa & 1.0148 & 0.0408 & 0.8702 & 1.0992 \\
\hline Idaho & 1.0156 & 0.0563 & 0.8890 & 1.1551 \\
\hline Illinois & 1.0070 & 0.0387 & 0.9301 & 1.0713 \\
\hline Indiana & 1.0135 & 0.0347 & 0.9273 & 1.0708 \\
\hline Kansas & 1.0165 & 0.0381 & 0.9278 & 1.0873 \\
\hline Kentucky & 1.0222 & 0.0426 & 0.9351 & 1.1311 \\
\hline Louisiana & 1.0205 & 0.0339 & 0.9421 & 1.0977 \\
\hline Massachusetts & 1.0109 & 0.0437 & 0.9435 & 1.0943 \\
\hline Maryland & 1.0129 & 0.0322 & 0.9346 & 1.0812 \\
\hline Maine & 1.0208 & 0.0675 & 0.8744 & 1.1770 \\
\hline Michigan & 1.0137 & 0.0474 & 0.9208 & 1.1584 \\
\hline Minnesota & 1.0160 & 0.0392 & 0.9213 & 1.1125 \\
\hline Missouri & 1.0136 & 0.0448 & 0.8992 & 1.1028 \\
\hline Missisippi & 1.0221 & 0.0369 & 0.9239 & 1.0867 \\
\hline Montana & 1.0154 & 0.0654 & 0.8324 & 1.1607 \\
\hline North Carolina & 1.0198 & 0.0339 & 0.9389 & 1.0812 \\
\hline North Dakota & 1.0229 & 0.0452 & 0.8697 & 1.1255 \\
\hline Nebraska & 1.0182 & 0.0523 & 0.8765 & 1.1215 \\
\hline New Hampshire & 1.0212 & 0.0609 & 0.8941 & 1.1793 \\
\hline New Jersey & 1.0099 & 0.0379 & 0.9323 & 1.1098 \\
\hline New Mexico & 1.0188 & 0.0562 & 0.8920 & 1.1535 \\
\hline Nevada & 1.0141 & 0.0749 & 0.8740 & 1.1660 \\
\hline New York & 1.0038 & 0.0265 & 0.9542 & 1.0480 \\
\hline Ohio & 1.0141 & 0.0319 & 0.9433 & 1.0812 \\
\hline Oklahoma & 1.0142 & 0.0468 & 0.9450 & 1.1711 \\
\hline Oregon & 1.0150 & 0.0612 & 0.8283 & 1.1750 \\
\hline Pennsylvania & 1.0123 & 0.0386 & 0.9490 & 1.1385 \\
\hline Rhode Island & 1.0117 & 0.0617 & 0.8972 & 1.1651 \\
\hline South Carolina & 1.0241 & 0.0437 & 0.9223 & 1.1573 \\
\hline South Dakota & 1.0215 & 0.0570 & 0.8565 & 1.1673 \\
\hline Tennessee & 1.0210 & 0.0466 & 0.9060 & 1.1392 \\
\hline Texas & 1.0146 & 0.0559 & 0.8517 & 1.1788 \\
\hline Utah & 1.0117 & 0.0467 & 0.8861 & 1.1193 \\
\hline Virginia & 1.0220 & 0.0440 & 0.9212 & 1.1166 \\
\hline Vermont & 1.0154 & 0.0636 & 0.8986 & 1.1813 \\
\hline Washington & 1.0102 & 0.0492 & 0.8854 & 1.1630 \\
\hline Wisconsin & 1.0148 & 0.0397 & 0.9297 & 1.1055 \\
\hline West Virginia & 1.0179 & 0.0570 & 0.8550 & 1.1010 \\
\hline Wyoming & 1.0206 & 0.0969 & 0.7256 & 1.2109 \\
\hline U.S. NIPA & 1.0125 & 0.0262 & 0.9614 & 1.0626 \\
\hline Average of States & 1.0154 & 0.0276 & 0.9621 & 1.0633 \\
\hline
\end{tabular}

Notes: Descriptive statistics for annual real growth in private consumption of nondurables and services. Figures are provided for 50 U.S. states and for the entire United States. Sample period: 1963-1995. State-level consumption series are constructed from retail sales data using procedures described in Del Negro (2002). All consumption series are deflated using the U.S. CPI. 


\begin{tabular}{|l|c|c|c|c|}
\hline \multicolumn{5}{|c|}{ Table 1B: Descriptive Statistics for Returns } \\
\hline & Mean & Stdev. & Min. & Max. \\
\hline & & & & \\
Dec-Dec, Value-weighted & 0.0568 & 0.1505 & -0.3038 & 0.3134 \\
Dec-Dec, Equally-weighted & 0.0851 & 0.1774 & -0.2736 & 0.4570 \\
Averaged, Value-weighted & 0.0526 & 0.1307 & -0.2790 & 0.3345 \\
Averaged, Equally-weighted & 0.0816 & 0.1485 & -0.2435 & 0.4600 \\
\hline
\end{tabular}

Notes: Descriptive statistics for yearly equity risk premia from 1963 to1995. The equity returns are value-weighted and equally-weighted indices, constructed by CRSP using NYSE and AMEX stocks. The Dec-Dec returns are yearly returns from December 31 of year $t$ to December 31 of year $t+1$. The averaged returns are constructed by computing the average of 12 yearly returns, namely the January-January, February-February, .... December-December returns. 


\begin{tabular}{|l|r|r|r|r|r|r|r|}
\hline \multicolumn{7}{|l|}{ Table 2A: Correlations between components of the pricing kernels and the Equity Premium } \\
December-December Returns, Value-Weighted \\
\hline \\
\hline
\end{tabular}

\begin{tabular}{|c|c|c|c|c|c|c|c|}
\hline \multicolumn{8}{|c|}{$\begin{array}{c}\text { Table 2B: Correlations between components of the pricing kernels and the Equity Premium } \\
\text { Averaged Returns, Value-Weighted }\end{array}$} \\
\hline & eq. risk prem. & U.S. c.gr. & average c.gr. & c.gr. moment 1 & c.gr. moment 2 & c.gr. moment 3 & c.gr. moment 4 \\
\hline \begin{tabular}{|l} 
eq. risk prem. \\
. rist
\end{tabular} & 1 & 0.2447 & 0.2406 & 0.2253 & -0.2662 & 0.2761 & -0.2171 \\
\hline U.S. c.gr. & 0.2447 & 1 & 0.9606 & 0.9585 & -0.3106 & -0.0038 & -0.3229 \\
\hline average c.gr. & 0.2406 & 0.9606 & 1 & 0.9989 & -0.2823 & 0.1373 & -0.3466 \\
\hline c.gr. moment 1 & 0.2253 & 0.9585 & 0.9989 & 1 & -0.2588 & 0.1391 & -0.3263 \\
\hline c.gr. moment 2 & -0.2662 & -0.3106 & -0.2823 & -0.2588 & 1 & 0.2656 & 0.8217 \\
\hline c.gr. moment 3 & 0.2761 & -0.0038 & 0.1373 & 0.1391 & 0.2656 & 1 & 0.1206 \\
\hline c.gr. moment 4 & -0.2171 & -0.3229 & -0.3466 & -0.3263 & 0.8217 & 0.1206 & 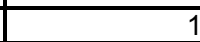 \\
\hline
\end{tabular}

Notes: Correlation matrices for returns and the first four moments of the cross-sectional distribution of consumption growth. The sample period is 1963-1995. The returns and growth variables are described in the notes to Tables $1 \mathrm{~A}$ and $1 \mathrm{~B}$, respectively. The first element in the correlation matrix is the equity risk premium. In Table $2 A$, the December-December returns are used; in Table 2B, the averaged returns are used instead. The second element in the correlation matrix is U.S. consumption growth. The third element is again consumption growth, this time computed using the equally-weigthed average of the state consumption levels. The next four elements are the first four moments of the cross-sectional distribution of state consumption growth. 


\begin{tabular}{|c|c|c|c|c|}
\hline & \multicolumn{2}{|c|}{ December-December returns } & \multicolumn{2}{|c|}{ Averaged returns } \\
\hline & Value-weighted & Equally-weighted & Value-weighted & Equally-weighted \\
\hline RA kernel (6) with aggregate US data & 60.13 & 96.10 & 41.40 & 62.82 \\
\hline RA kernel (6) based on average of state consumption & 52.99 & 74.21 & 36.86 & 55.18 \\
\hline Standard incomplete-markets kernel (5) & $14.86\left(^{*}\right)$ & $12.09\left(^{*}\right)$ & 18.19 & 22.48 \\
\hline Incomplete markets kernel with first moment (8) & 53.23 & 74.11 & 37.59 & 56.14 \\
\hline Incomplete markets kernel with first two moments (9) & 32.29 & 44.77 & 27.39 & 40.95 \\
\hline Incomplete markets kernel with first three moments (10) & 30.77 & 40.04 & 24.24 & 34.42 \\
\hline Incomplete markets kernel with first four moments (7) & 30.29 & 51.09 & 28.77 & 33.65 \\
\hline Constantinides-Duffie incomplete-markets kernel (11) & 26.36 & 57.29 & 23.14 & 33.36 \\
\hline Incomplete-markets kernel, population-based weights (12) & $22.64\left({ }^{*}\right)$ & $18.11\left(^{*}\right)$ & 24.26 & 29.35 \\
\hline
\end{tabular}

Notes: Each cell represents the rate of risk aversion that equates to zero the difference between the Euler equation for the risky asset and the Euler equation for the riskless asset. In some cases, no rate of risk aversion is available that equates this expression to zero. In these cases the rate of risk aversion that yields the lowest pricing error is reported. These cases are indicated with an (*). Return variables are described in Table $1 \mathrm{~B}$. 
Figure 1: The Equity Risk Premium and the Moments of the Cross-Sectional Distribution of Consumption Growth over Time
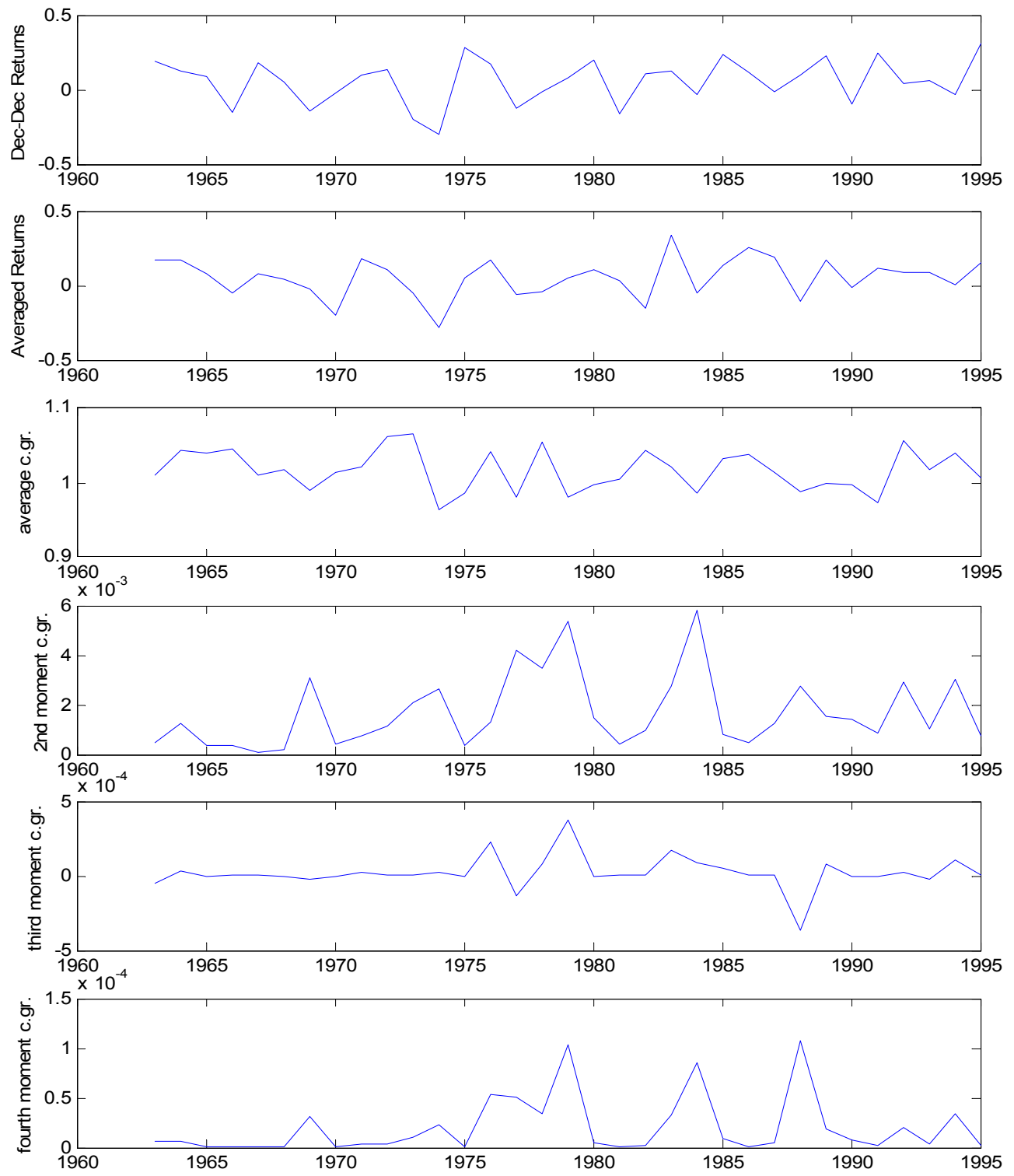

Notes: The top two panels represent returns as a function of time. The bottom four panels represent the first four moments of the cross sectional distribution of consumption growth. At each point in time, these moments are computed using consumption growth data on 50 U.S. states for 1963-1995. Returns and consumption growth variables are described in the notes to Tables 1A and $1 \mathrm{~B}$, respectively. 
Figure 2: Pricing Errors for Different Pricing Kernels as a Function of Risk Aversion
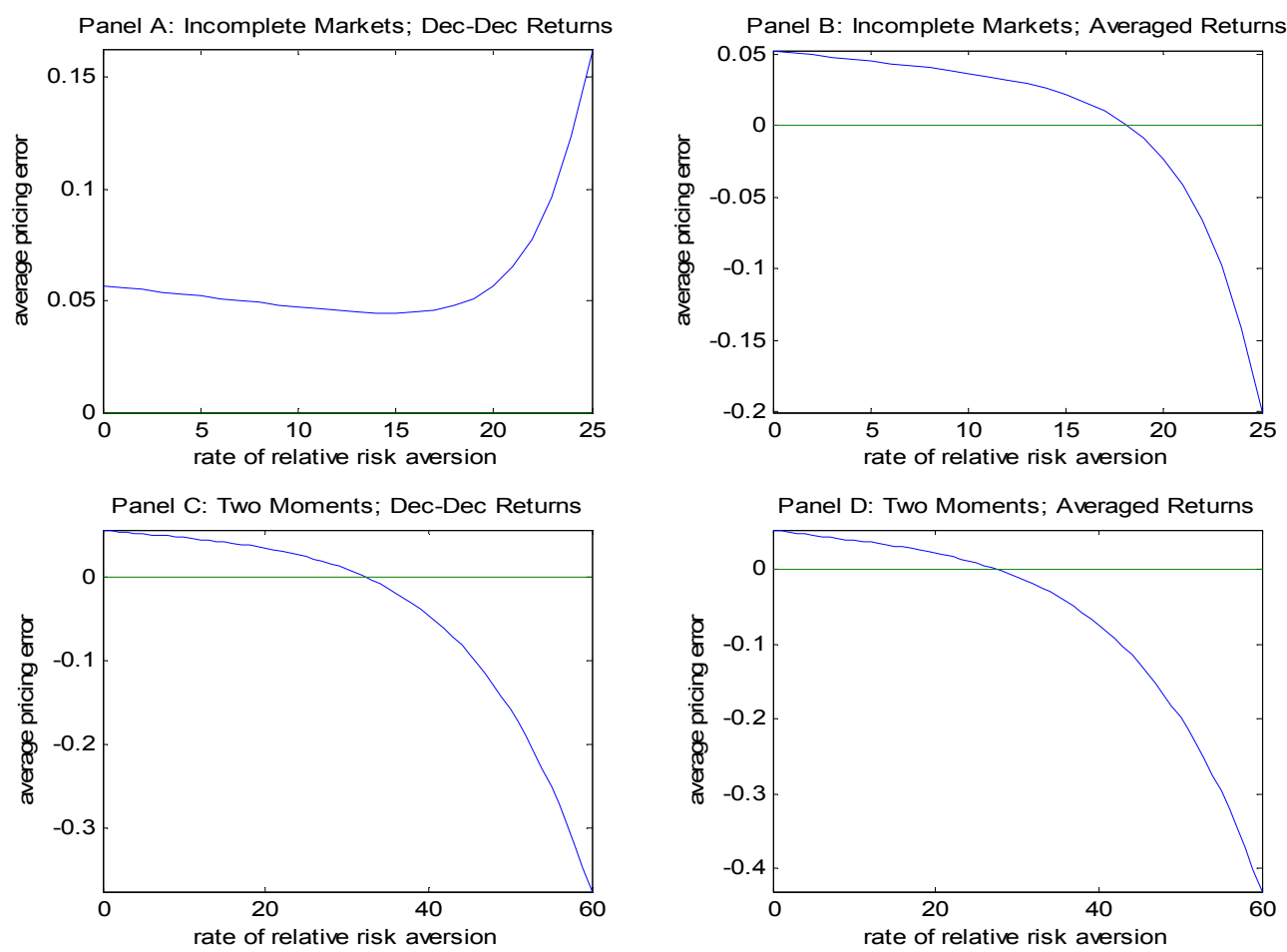

Notes: Each panel gives average pricing errors as a function of risk aversion. Panel A presents results for the standard incomplete markets kernel in (5), using December-December returns. Panel B presents results for the same standard incomplete markets kernel, using averaged returns. Panel C presents results for the incomplete markets kernel with the first two moments in (9), using December-December returns. Panel D presents results for the incomplete markets kernel with the first two moments in (9), using averaged returns. The return variables are described in the notes to Table 1B. 
Figure 3: Confidence Bands for Different Pricing Kernels as a Function of Risk Aversion
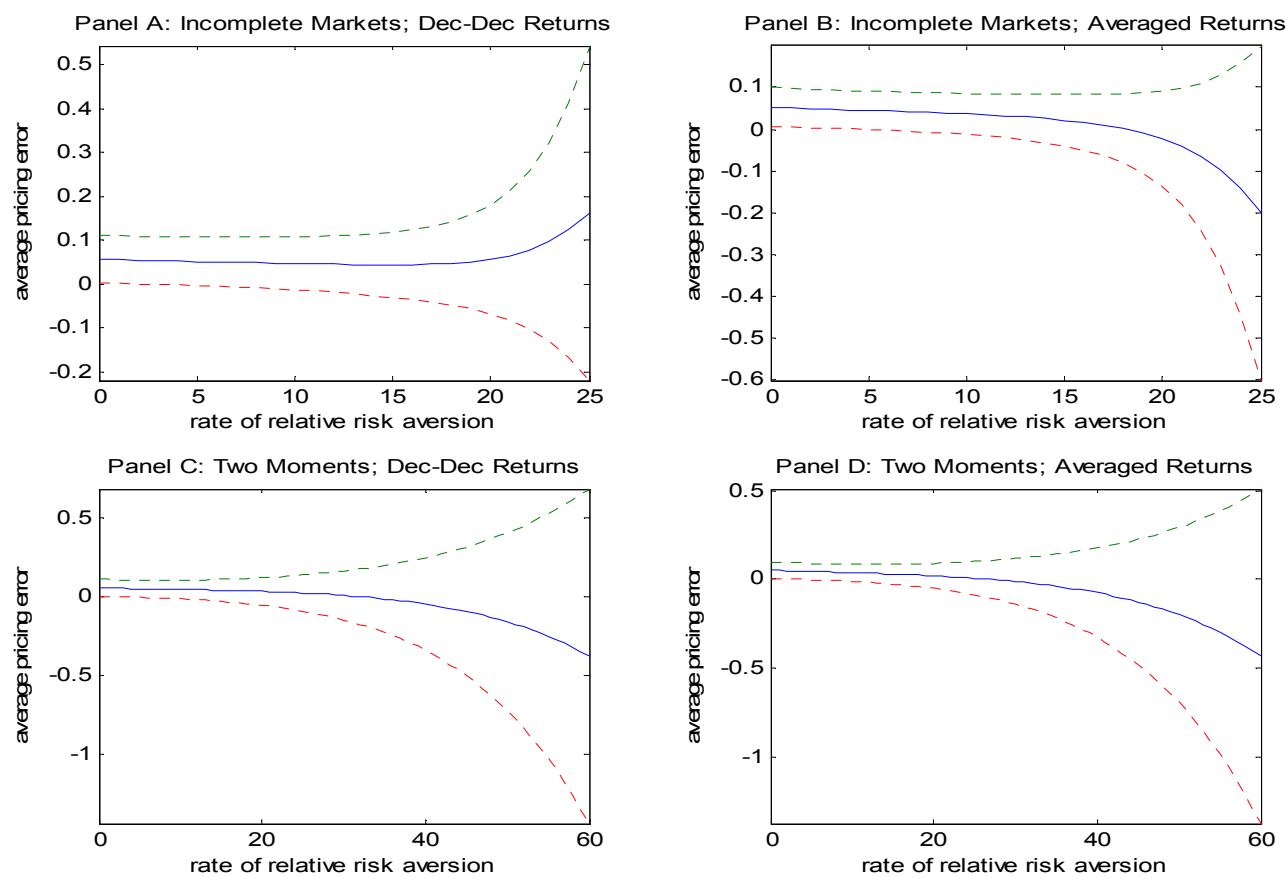

Notes: Each panel gives average pricing errors (solid lines) and the 95\% confidence intervals (dotted lines) as a function of risk aversion. Standard errors are computed assuming no serial correlation. Panel A presents results for the standard incomplete markets kernel in (5), using December-December returns. Panel B presents results for the same standard incomplete markets kernel, using averaged returns. Panel $\mathbf{C}$ presents results for the incomplete markets kernel with the first two moments in (9), using December-December returns. Panel D presents results for the incomplete markets kernel with the first two moments in (9), using averaged returns. The return variables are described in the notes to Table $1 \mathrm{~B}$. 